\title{
Assistive Technologies for Visually Impaired Users on Android Mobile Phones
}

\author{
Aishwarya A. Sagale \\ Information \& Technology Dept. \\ Pimpri Chinchwad College of Engineering \\ Pune, India
}

\author{
Anagha Chaudhari \\ Information \& Technology Dept. \\ Pimpri Chinchwad College of Engineering \\ Pune, India
}

\begin{abstract}
With the increasing number of mobile phone users, mobile phones have become important means of communication and information sharing. Mobile phone users consist of sighted users and visually impaired users. Touchscreen mobile phones are inaccessible for visually impaired users due to the absence of any physical keys and insufficient accessibility features. An effective assistive technique for interacting with mobile phones may solve inaccessibility problem. This study describes various assistive applications currently available for different functionalities in mobile phones. These assistive applications provided accessibility for detecting surrounding and helping with direction. The study helps in understanding various techniques used. These techniques include Speech to Text converter, Text to Speech converter and various image recognition algorithms. The study and comparison of all these currently available applications and techniques is very important for proposing new application.
\end{abstract}

\section{General Terms}

Assistive Technologies, Accessibility, Image Recognition.

\section{Keywords}

Mobile Phone, Visually Impaired, Touchscreen Mobile Phone, Assistive Technology.

\section{INTRODUCTION}

According to the Telecom Regulatory Authority of India (TRAI), February 2018, there are 1156.87 million mobile phone subscribers in India, out of which 650.03 million subscribers are in urban region while 506.84 million are in rural region. The TRAI data (February 2018) also suggests that the mobile phone tele-density, that is, the number of mobile phones in use for every 100 individuals living within an area, of India has reached 89.12 [10]. Hence, it can be said that the number of mobile users, who are 1156.87 million out of 1340 million projected population of India (1210 million according to Census 2011), is very large [9]. Such large population of mobile phone users can be categorized into two major groups. One group has abled users while the other has differently-abled users having various disabilities. Differentlyabled users can be further classified as users having disabilities with vision, hearing, speech, limb and others. Users with vision disability, which are also referred as visually impaired users, form the major subgroup of differently-abled users [8].

\subsection{Visually Impaired Users}

Visually impaired users can be sub-grouped as partial visually impaired users and total visually impaired users. The visual acuity of the partial visually impaired user is less than $6 / 18$, but equal to or better than $3 / 60$, or a corresponding visual field loss to less than 20 degrees in the better eye with best possible correction. The visual acuity of total visually impaired user is less than $3 / 60$, or a corresponding visual filed loss to less than 10 degrees in the better eye with best possible correction [5].

The estimates of World Health Organization (2010) depicts that the total number of visually impaired people in world is 285 million, out of which 39 million are total blind and 246 million are partial blind. Estimates also shows $90 \%$ of the visually impaired population lives in developing countries.

\subsection{Assistive Technologies}

The increasing number of mobile phones had made it the major means of communication as well as source of information. Hundreds and thousands of applications are developed daily and placed in Google Play for users to download. However, visually impaired users cannot access all these applications. These users face tremendous difficulties in accessing touchscreen mobile phones unlike the sighted users. These users had to adapt to the error-prone strategies to use mobile phones or find accessible alternatives. The inaccessibility of the mobile phones is due to interaction techniques that require the user to visually locate objects on the screen. This problem can be solved by the assistive technologies. Assistive technologies enable visually impaired user to access mobile phones with ease.

Android version 1.6 had introduced the feature of accessibility which is the basic assistive technology. The accessibility has been constantly improving thereafter in later versions. Android based mobile phones provide a self-voice interface upon which programmers / developers can build their own applications [7]. However, currently there are few assistive technologies or application and features available. These features are still in developing phase and still improving to provide better accessibility. Therefore, it is of vital importance to design assistive technologies or an effective interaction technique to make mobile phones accessible for visually impaired users.

\section{ASSISTIVE APPLICATIONS}

Currently there are few accessibility applications available for mobile phones for different functionalities. These applications are in different phases of development, some are freely available in Google Play Store while some are still in development phase. Six such applications are studied.

\subsection{Intelligent Eye}

Awad et al. had introduced an application named 'Intelligent Eye'. This application offers multiple features in single application to visually impaired users. These features include light detection, colour detection, object recognition, and banknote recognition. Light detection uses embedded light sensor and tells the intensity of and nature of light with the help of different pitched sound and speech respectively. Colour detection uses primary camera to capture the surrounding area and tells colour of area which is touched on 
screen by user. Object recognition identifies the objects captured by primary camera. Similarly, banknote recognition identifies the banknote which is captured by primary camera. All the output is provided to the user in the form of voice and speech. Fig. 1 shows home screen of Intelligent Eye [1].

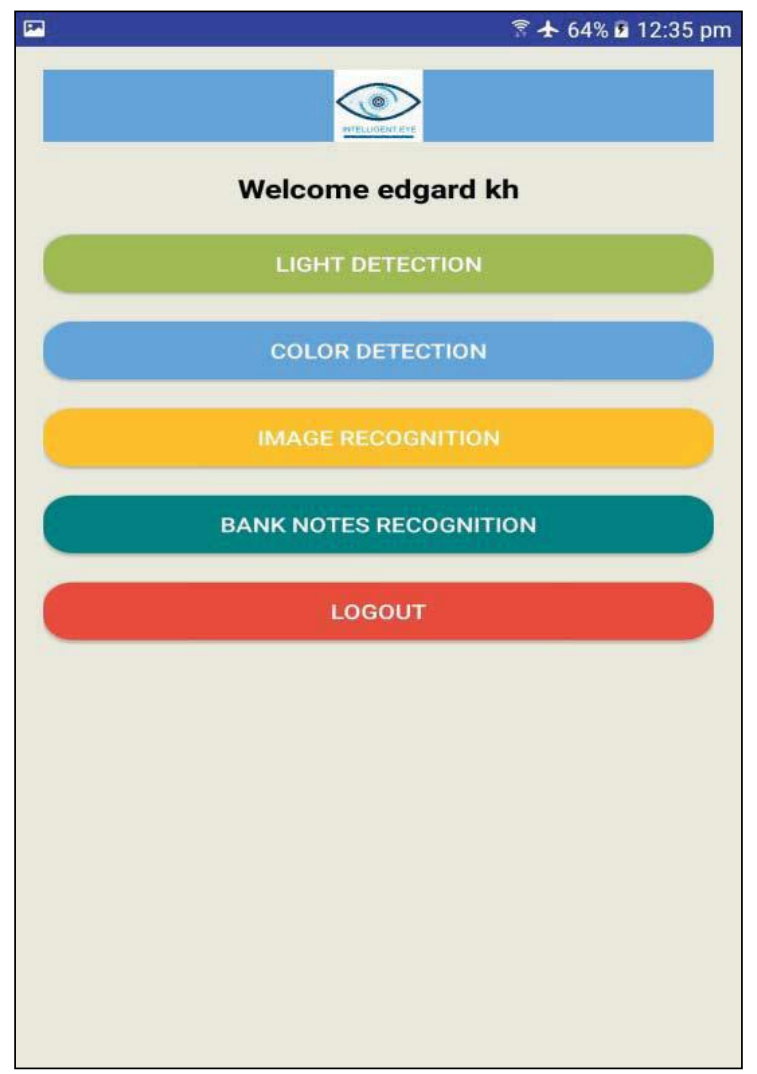

Fig 1: Intelligent Eye: Home Screen

\section{2 iCu₹̄e}

Raval et al. had proposed an application named 'iCu₹e'. This application helps visually impaired user to identify Indian currency notes or coins. The whole processing of the application is divided into three major parts. These parts are Image Capture, Image Identification and Text-to-Speech Conversion. In Image Capture, visually impaired user captures the image of currency note or coin using mobile phone camera. This image is reset by segmentation and removing the background captured. In Image Identification, various image processing techniques such as Histogram, Vector Quantization and Feature Extraction are used in combination to detect the currency note or coin. The detected note or coin value is provided to next part, that is, Text-toSpeech Conversion. This part conveys the currency value to the visually impaired user with the help of speech. The sequence of the processes in currency note or coin recognition is shown in Fig. 2. The application 'iCu₹e' is still in development phase and proposes to implement more efficient algorithm for currency detection [4].

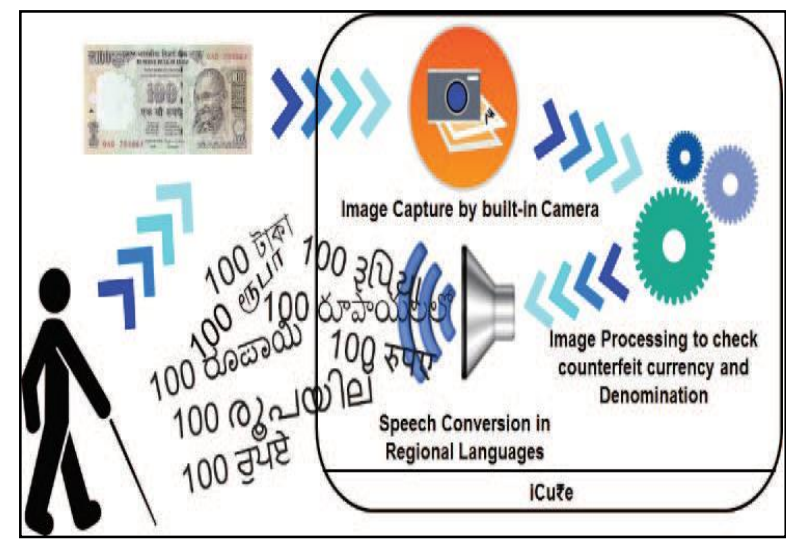

Fig 2: Intelligent Eye: Home Screen

\subsection{Emergency Exit Sign Detection}

Swathika et al. had proposed an Android application for identifying emergency exit sign. The motive behind this application is to enable visually impaired users to identify the exit direction in case of emergency situation and get to the safety without the need of assistance from other normally sighted people.

As the image captured by different mobile phones can be of various sizes, author resizes all image to $300 * 300$ resolution to help processing large sized images. This image in then converted to grayscale. Then image is blurred using median filter which helps eliminating salt and pepper noise which removes smaller darks spot present on the image. This helps in detection of edges in the image. This edge detected image is provided to region detection module. This module uses the bounding box algorithm to detect the bounding rectangle of the exit sign which is cropped and provided to next module for further processing. Then next module, region extraction, identifies and divides the image into two regions containing exit sign region and exit direction. Exit sign region confirm the existence of emergency exit sign. The exit direction region is matched with the template available in dataset and then decide the exact direction of the exit. This direction is provided to visually impaired user with the help of voice output [6].

Fig. 3 shows the system diagram for this application. Fig. 4 shows the original image captured using mobile phone camera and the processed image having just the exact Exit Sign region.

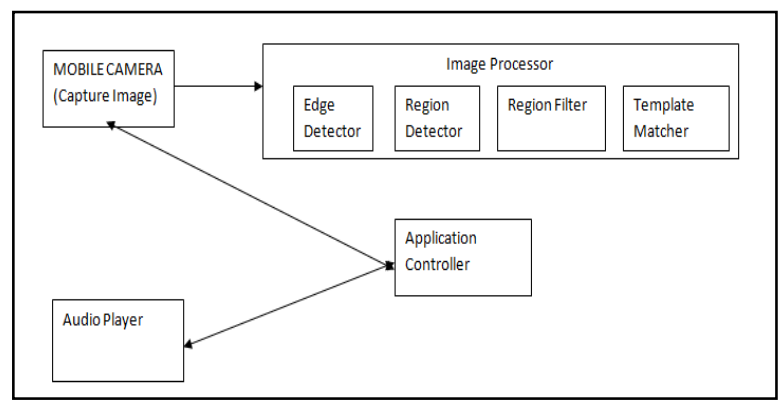

Fig 3: Emergency Exit Sign Detection System Diagram 


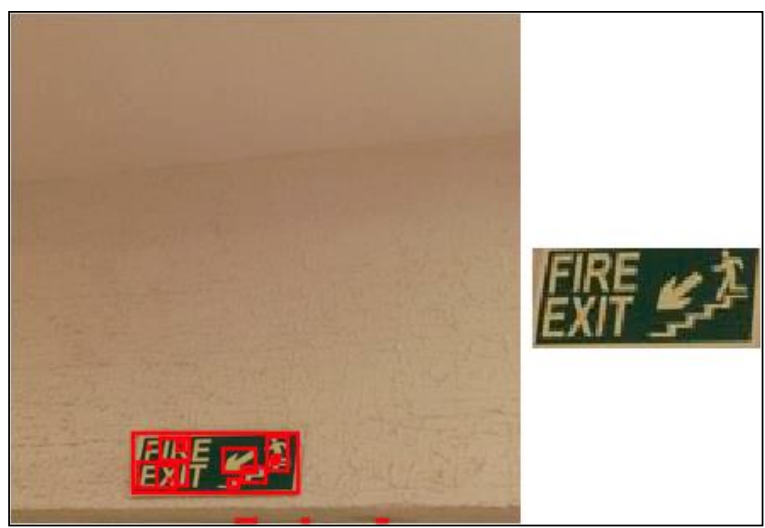

Fig 4: Original Emergency Exit Sign Image Captured and Detected Exit Sign Region

\subsection{Automatic Number Plate Recognition}

Jogekar et al. had proposed an application which can capture the image of the vehicle number plate and detect the number. The image of vehicle number plate is captured using mobile phone camera. The size of image is reduced to $300 * 300$ using image normalization. This resized image is then converted into grayscale. The grayscale image is lured using various techniques like Gaussian, Median and Kalman. Blurring image reduced noise present in image. This image is provided to OCR module. In this module the characters on number plate are detected from image and exact vehicle number is detected. The detected vehicle number is provided to the user. This will help visually impaired user in identifying the correct vehicle to get in [3]. Fig. 5 shows the image captured using mobile phone camera and the detected vehicle number.

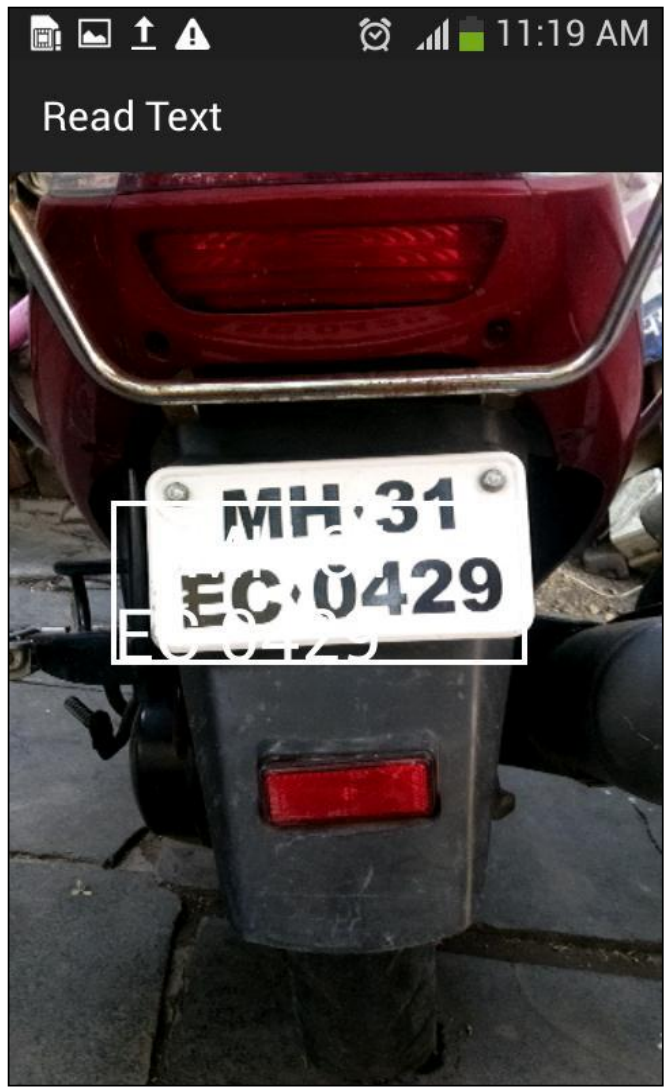

Fig 5: Vehicle Number Plate Detection

\subsection{VisualPal}

Bagwan et al. had proposed an application named 'VisualPal'. This application detected direction of maximum light, colour and the object in surrounding. In detection of direction of maximum light, mobile phone camera is live capturing the image like the video shooting. Image processing is used to detect the change in intensity of light in the region. As the intensity of light increases, the frequency of sound increases and vice versa. This can help partially blind users in navigating from area on low light to the area with more light.

In colour detection module, RBG image captured using mobile phone camera is converted into HSV image. Colour components are separated from the intensity of various regions and shadows are removed. ' $\mathrm{H}$ ' component represents the actual colour which is used or colour detection. Average of ' $\mathrm{H}$ ' components are taken and colour of whole image is determined. This can help visually impaired users in detecting the colour or particular region or object. In object detection module, user can add new training objects to incorporate new object which can be detected later on. This module uses combination or Artificial Neural Network (ANN) and Euclidean distance measures. These algorithms are used to training and detection of the objects depending on the dataset collected in training. This can help visually impaired user in recognizing the objects in the surrounding. All the detections are provided to the visually impaired user with the help of voice output [2]. Fig. 6 shows the object detection module of 'VisualPal'.

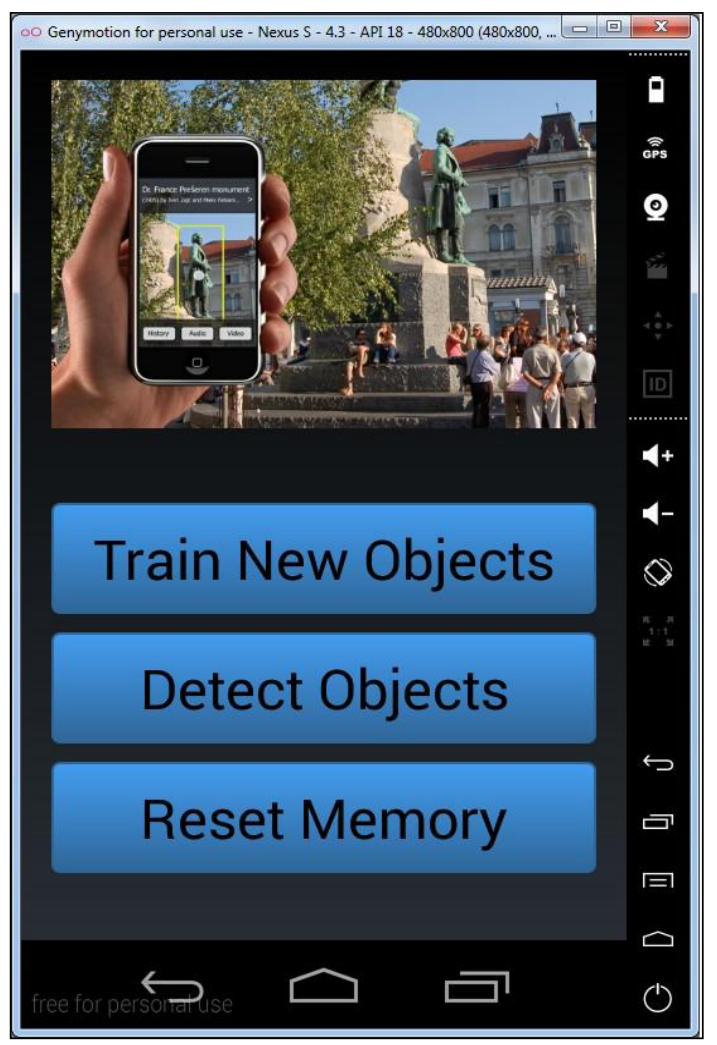

Fig 6: Object Detection Module of VisualPal

\section{COMPARISON STUDY}

Table 1 and 2 shows that comparative study of the five assistive applications in Mobile Phones for Visually Impaired users. In this table, five applications are compared based on their purpose, special requirement, technique, input and output. 
Table 1. Comparison Table 1

\begin{tabular}{|c|c|c|c|}
\hline Application & $\begin{array}{c}\text { Intelligent } \\
\text { Eye }\end{array}$ & iCu₹e & $\begin{array}{c}\text { Emergency } \\
\text { Exit Sign } \\
\text { Detection }\end{array}$ \\
\hline Purpose & $\begin{array}{l}\text { Light, } \\
\text { Color, } \\
\text { Object and } \\
\text { Banknote } \\
\text { Recognition }\end{array}$ & $\begin{array}{c}\text { Detect } \\
\text { Indian } \\
\text { Currency } \\
\text { Notes \& } \\
\text { Coins }\end{array}$ & $\begin{array}{l}\text { Detect Exit } \\
\text { Sign }\end{array}$ \\
\hline $\begin{array}{c}\text { Special } \\
\text { Requireme } \\
\text { nt }\end{array}$ & $\begin{array}{c}\text { Object and } \\
\text { Currency } \\
\text { Dataset }\end{array}$ & $\begin{array}{c}\text { Indian } \\
\text { Currency } \\
\text { Dataset }\end{array}$ & $\begin{array}{c}\text { Adequate } \\
\text { Light }\end{array}$ \\
\hline Technique & $\begin{array}{c}\text { OpenCV, } \\
\text { CraftAR } \\
\text { Library, } \\
\text { CNNdroid }\end{array}$ & $\begin{array}{l}\text { Histogram, } \\
\text { Vector } \\
\text { Quantizatio } \\
\text { n, Feature } \\
\text { Extraction }\end{array}$ & $\begin{array}{c}\text { Edge \& } \\
\text { Region } \\
\text { Detection, } \\
\text { Region } \\
\text { Extraction, }\end{array}$ \\
\hline Input & $\begin{array}{c}\text { Currency } \\
\text { Note Image, } \\
\text { Object } \\
\text { Image }\end{array}$ & $\begin{array}{l}\text { Currency } \\
\text { Note Image }\end{array}$ & $\begin{array}{l}\text { Exit Sign } \\
\text { Image }\end{array}$ \\
\hline Output & $\begin{array}{l}\text { Light, } \\
\text { Color, } \\
\text { Object and } \\
\text { Currency } \\
\text { Note as } \\
\text { Audio }\end{array}$ & $\begin{array}{l}\text { Currency } \\
\text { Note Value } \\
\text { as Audio }\end{array}$ & $\begin{array}{c}\text { Exit Sign } \\
\text { Detection \& } \\
\text { Direction of } \\
\text { Exit as } \\
\text { Audio }\end{array}$ \\
\hline
\end{tabular}

Table 2. Comparison Table 2

\begin{tabular}{|c|c|c|}
\hline Application & $\begin{array}{l}\text { Automatic } \\
\text { Number Plate } \\
\text { Recognition }\end{array}$ & VisualPal \\
\hline Purpose & $\begin{array}{l}\text { Extract Text and } \\
\text { Numbers }\end{array}$ & $\begin{array}{c}\text { Detect the } \\
\text { Objects, Light } \\
\text { Intensity and } \\
\text { Colour Detection }\end{array}$ \\
\hline $\begin{array}{c}\text { Special } \\
\text { Requirement }\end{array}$ & $\begin{array}{l}\text { Steady Vehicle and } \\
\text { Alpha-Numeric } \\
\text { Dataset }\end{array}$ & Object Dataset \\
\hline Technique & $\begin{array}{c}\text { Canney Algorithm } \\
\text { (Optical Character } \\
\text { Recognition) }\end{array}$ & $\begin{array}{c}\text { Blurring, Edge \& } \\
\text { Boundary } \\
\text { Detection, } \\
\text { Thresholding }\end{array}$ \\
\hline Input & $\begin{array}{l}\text { Number Plate } \\
\text { Image }\end{array}$ & Object Image \\
\hline Output & $\begin{array}{c}\text { Vehicle Number as } \\
\text { Audio }\end{array}$ & $\begin{array}{c}\text { Object } \\
\text { Description as } \\
\text { Audio }\end{array}$ \\
\hline
\end{tabular}

Based on above comparison, below comments are made:

- All applications have speech output, however, VisualPal also provides sound output with increased or decreased frequency depending on light intensity.

- Emergency Exit Sign detector is to be used in case of emergency situations, however, if lighting conditions are low then it will affect image capturing and in turn application efficiency.

- Intelligent Eye and iCu₹e are very useful to visually impaired users during cash transactions. However, these applications cannot confirm the authenticity of currency.

- VisualPal have object training by user. This increases the scope of objects that can be detected using the application. Only downside is, it increases user's load of creating training set.

- Automatic number plate recognition can help visually impaired user detecting correct vehicle. However, vehicle needs to be stationary for get good quality image.

\section{CONCLUSION}

Five assistive applications for Visually Impaired users having different purpose are studied. The study provides the comparison about various aspects of these applications. The study will help in designing new accessible application. The new application can be having multiple features targeting different aspects for the daily routine of the visually impaired user such as identifying surrounding area and people, helping managing daily schedule, navigating through surrounding area and travelling from one place to other and many more.

\section{REFERENCES}

[1] Awad M., Haddad J., Khneisser E., Mahmoud T., Yaacoub E. and Malli M., "Intelligent Eye: A Mobile Application for Assisting Blind People". 2018 IEEE Middle East and North Africa Communications Conference. ISBN: 978-1-5386-1254-5/18.

[2] Bagwan S. and Sankpal L., "VisualPal: A Mobile App for Object Recognition for the Visually Impaired". IEEE International Conference on Computer, Communication and Control (IC4-2015).

[3] Jogekar R., Dhoble A., Kakde S., Taklikar P. and Larokar D., "Automatic Number Plate Recognition System Through Smart Phone Using Image Processing", International Research Journal of Engineering and Technology (IRJET), Volume: 04 Issue: 03, Mar -2017. e-ISSN: 2395 -0056.

[4] Raval V. and Shah A., "iCu₹e - An IoT Application for Indian Currency Recognition in Vernacular Languages for Visually Challenged People", $20177^{\text {th }}$ International Conference on Cloud Computing, Data Science \& Engineering - Confluence. IEEE ISBN: 978-1-50903519-9/17.

[5] Resnikoff S., Pascolini D., Etyáale D., Kocur I., Pararajasegaram R., Pokharel G. and Mariotti S., "Global Data on Visual Impairment in the Year 2002". Bulletin of the World Health Organization, Nov. 2004, 82(11).

[6] Swathika R. and Sharmila T., "Emergency exit sign detection system for visually impaired people", 2016 International Conference on Inventive Computation Technologies. IEEE, Online ISBN 978-1-5090-1285-5.

[7] Torcolini C.: "Improving Accessibility for the Blind on the Android Platform". Thesis report, (2010).

[8] http://apps.who.int/iris/bitstream/handle/10665/43737/97 89241547321_eng.pdf - International Classification of Functioning, Disability and Health (2007) by World Health Organization. Accessed on 27th April 2018.

[9] http://censusindia.gov.in/2011-provresults/prov_rep_tables.html - Census data India, 2011 Accesses on 27th April 2018.

[10] http://trai.gov.in/sites/default/files/PRTSDEng24042018. pdf - TRAI Mobile Subscription Data (February 2018). Accessed on 27th April 2018. 